\title{
Intraperitoneal Bupivacaine as Post-laparoscopic Cholecystectomy Analgesia
}

\author{
Abdul Manan, Ashar Ahmad Khan, Irfan Ahmad, Muhammad Usman, Tariq Jamil and Muhammad Afzal Sajid \\ Department of Surgery IV, Nishtar Medical University, Nishtar Road, Gillani Colony, Multan, Pakistan
}

\begin{abstract}
Objective: To assess the efficacy of large volumes of diluted intraperitoneal bupivacaine in post-laparoscopic cholecystectomy analgesia.

Study Design: A randomised controlled trial.

Place and Duration of Study: Department of General Surgery, Nishtar Hospital, Multan, from August 2018 to June, 2019. Methodology: Two equal groups with 55 patients each were formed. Normal saline $500 \mathrm{ml}$ in group A, and mixture of $20 \mathrm{ml}$ $0.5 \%$ bupivacaine in $480 \mathrm{ml}$ normal saline in group B, was used to irrigate peritoneal cavity. Final outcome of the study was the comparison of pain-free duration. Postoperatively, numerical rating scale (NRS) score at various intervals and total analgesics requirement within 24 hours after the procedure were included in the secondary outcomes. Student's t-test was applied on continuous data and Pearson's Chi-square test on nominal variables. P $>0.05$ was considered of no statistical significance.

Results: Both groups were comparable for age, weight, gender, duration of surgery. Postoperative analgesia duration was $0.99 \pm 0.51$ hours in group $A$ and $16.53 \pm 2.65$ hours in group-B $(p<0.001)$. On average, $124.80 \pm 26.68 \mathrm{mg}$ and 31.00 $\pm 14.98 \mathrm{mg}$ tramadol was given to group $A$ and $B$ patients, respectively $(p<0.001)$. There was statistically significant difference in NRS score at 30 minutes, $1,3,6$ and 12 hours postoperatively $(p<0.05)$. NRS score at ETT extubation and at 24 hours was statistically not different $(p>0.05)$.

Conclusion: Large volume of diluted bupivacaine when injected intraperitoneally during laparoscopic cholecystectomy provides prolonged time pain relief.
\end{abstract}

Key Words: Laparoscopic cholecystectomy (LC), Intraperitoneal, Postoperative analgesia, Bupivacaine.

How to cite this article: Manan A, Khan AA, Ahmad I, Usman M, Jamil T, Sajid MA. Intraperitoneal bupivacaine as post-laparoscopic cholecystectomy analgesia. J Coll Physicians Surg Pak 2020; 30(1):9-12.

\section{INTRODUCTION}

Laparoscopic cholecystectomy (LC) has become a very popular procedure for treating non-malignant diseases of gall-bladder. Short hospital stay and decreased postoperative pain are the benefits of laparoscopic technique as compared to open cholecystectomy. 1,2 Still, within first 24 postoperative hours, patients mostly complain of pain. 3,4 Numerous opioid as well as non-opioid analgesics have been used in order to reduce post-LC pain, with variable success rates. Pain is of parietal origin in open cholecystectomy. About $17-41 \%$ of the patients who underwent LC have to stay for at least only one day in the hospital due to postsurgical pain; and these patients take long time for rehabilitation.

Specialists suggest multi-modal approach for treating the post LC pain as it is very complex entity. Multi-modal treatment approach for post-LC pain includes the

Correspondence to: Dr. Abdul Manan, Department of Surgery IV, Nishtar Medical University, Nishtar Road, Gillani Colony, Multan, Pakistan

E-mail: drmanan2001@yahoo.com

Received: August 20, 2019; Revised: December 16, 2019;

Accepted: December 26, 2019 empathy building; and explaining the procedure as well as its impediments to the patients, confidence building of patients, and administering of NSAIDs prior to the commencement of the surgical procedure. Other modalities for reducing the postoperative pain are perioperative administration of the opioid analgesics, local anesthetic infiltration of the incision sites, and peritoneal cavity irrigation with local anesthetics. It is still a challenge for the experts to provide effective post-LC analgesia.

Peritoneal cavity irrigation with various local anesthetic drugs for post-LC analgesia has become a very popular practice in past few years. In some studies, highly concentrated bupivacaine in low volumes, i.e. $20 \mathrm{ml}$ in $100 \mathrm{ml}$ normal saline was used to achieve post-LC analgesia; but the duration of post-operative analgesia was not sufficiently long. ${ }^{5-8}$ On the other hand, diluted bupivacaine in huge volumes i.e. $20 \mathrm{ml}$ in $500 \mathrm{ml}$ normal saline was used to achieve post-LC analgesia and the duration of postoperative was effectively long and depth of analgesia was also adequate. ${ }^{9}$ Large volumes can reach all the areas in the sub-hepatic region and produce adequate analgesia, which can be the ultimate reason for promising results in the study, using large volumes of diluted local anesthetic. 
Research data to support effectiveness of high volumes of diluted bupivacaine in producing effective post-LC analgesia when used to irrigate the peritoneal cavity during surgical procedure, is scarce. Moreover, local studies are also not available.

Current study was planned to assertain the effectiveness of large volumes of low concentration bupivacaine in producing post-LC analgesia, when used for peritoneal cavity irrigation during surgical procedure.

\section{METHODOLOGY}

This randomised controlled trial was conducted at Department of General Surgery, Nishtar Hospital, Multan from August 2018 to June 2019. Ethical approval was obtained from the Hospital Review Committee. A total of 110 patients of ASA grade I and grade II were selected by nonprobability consecutive sampling technique. Sample size was calculated using NRS score at postoperative 6 hours from the reference study with the help of OpenEpi toolkit. 9 The age of all the patients was 18-60 years and they all were candidates of elective LC under general anesthesia. Pregnant women, patients taking opioid analgesics, having choledocholithiasis, acute pancreatitis or chronic pain, and those who were allergic to local anesthetic agents were not included in the study. Patients whose procedure was converted to open cholecystectomy were also excluded from the study.

Informed consent was signed by every patient before enrollment in the study. Patients were explained about the details of the numeric pain rating scale i.e. 0 being no pain at all to 10 being extremely severe pain. Oral feeding of all the patients was stopped at least 8 hours before surgery. Diclofenac sodium was used to achieve analgesia during the surgery. It was administered intravenously at $1.5 \mathrm{mg} / \mathrm{kg}$ dose. During the procedure, no other analgesics were given.

A total of 115 patients underwent LC, but five were excluded as per exclusion criteria (Figure 1). Two equal groups with 55 patients each were formed with random allotment of patients. Lottery system was used and every patient was asked to pick an enclosed token with his/her study group mentioned on it. Normal saline of $500 \mathrm{ml}$ was used in group A to irrigate the peritoneal cavity. Peritoneal cavity was flooded with a mixture of $20 \mathrm{ml} 0.5 \%$ bupivacaine in $480 \mathrm{ml}$ normal saline in group B. Half of irrigation fluids were injected before the start of gallbladder dissection and aspirated after completing the dissection. After extracting the gallbladder, peritoneal cavity and surgical bed were irrigated with remaining halves of the irrigation fluids. Patients were put in Trendelenburg's position with tilt on the right side for five minutes to facilitate the dispersal of fluid to right subhepatic area. Intravenous tramadol $2 \mathrm{mg} / \mathrm{kg}$ was given to provide rescue analgesia. Analgesia duration was labelled as the time from the end of surgical procedure to the time when first rescue analgesia was given. Rescue analgesics was provided when NRS score was $\geq 4$. NRS score was documented postoperatively at 30 minutes, 1, 3, 6, 12 and 24 hours, respectively.

Final outcome of current study was comparison of painfree duration. NRS score at various intervals and total analgesics requirement within 24 hours after the procedure were included in the secondary outcomes. The data was collected on preformed proformas. Data was analysed with SPSS version 23.0. Student's t-test was applied on continuous data and Pearson's Chi-square test on nominal variables. The $p>0.05$ was considered of no statistical significance.

\section{RESULTS}

The mean age of group A patients was $44.42 \pm 10.78$ years and of group $B$ patients was $44.22 \pm 10.45$ years $(p=0.921)$. Average weight of group $A$ and $B$ patients was $56.76 \pm 9.10 \mathrm{~kg}$ and $55.29 \pm 8.10 \mathrm{~kg}$, respectively $(p=0.374)$. Group A included 29 males and 26 females; while group $B$ included 22 males and 33 females $(p=0.181)$. Total surgical time was $60.20 \pm 5.42$ minutes and $59.45 \pm 5.77$ minutes in group $A$ and $B$, respectively $(p=0.486$, Table I).

Mean postoperative analgesia duration was $0.99 \pm 0.51$ hours in group A patients and $16.53 \pm 2.65$ hours in group B patients ( $p<0.001)$. On average, $124.80 \pm 26.68 \mathrm{mg}$ tramadol was given to group $A$ patients and 31.00 $\pm 14.98 \mathrm{mg}$ tramadol was given to group B patients $(p<0.001)$. On extubation, mean NRS score was 1.18 \pm 0.86 and $0.96 \pm 0.78$ in group $A$ and $B$, respectively; and difference was statistically insignificant $(p=0.205)$. Mean NRS score was $1.71 \pm 1.08$ and $1.22 \pm 0.78$ at 30 minutes; $1.96 \pm 0.99$ and $1.60 \pm 0.56$ at 1 hour; $2.89 \pm 1.26$ and $2.20 \pm 1.11$ at 3 hours; $3.53 \pm 0.90$ and $2.33 \pm 1.04$ at 6 hours; and $4.09 \pm 1.09$ and $3.64 \pm 0.87$ at 12 hours postoperatively in group $A$ and $B$, respectively. The differences were statistically significant at 30 minutes,

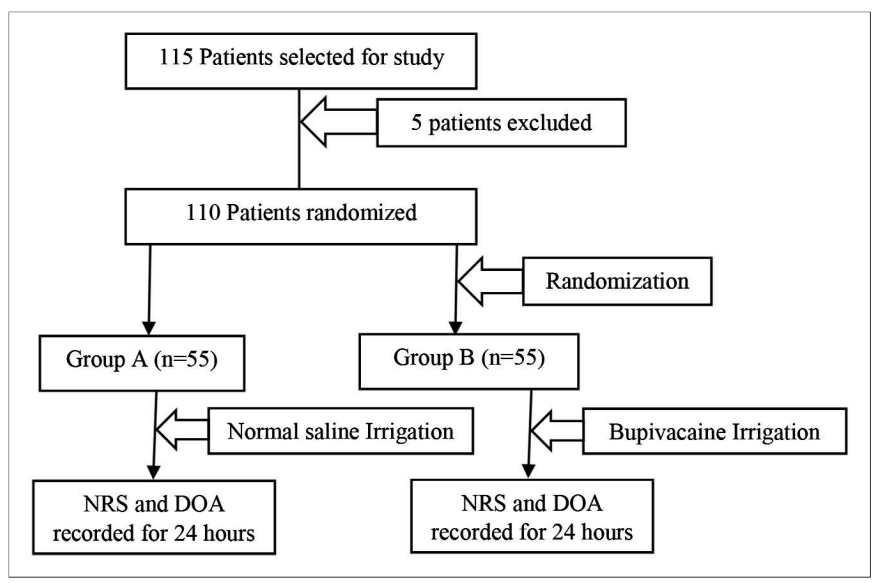

Figure 1: Consort diagram.

NRS $=$ Numerical pain rating score; $D O A=$ Duration of analgesia 
$1,3,6$ and 12 hours $(p=0.008,0.021,0.003,<0.001$ and 0.017 , respectively). At postoperative 24 hours, mean NRS was $4.80 \pm 0.99$ in group $A$, and $4.44 \pm 1.03$ in group $B$; and the difference was statistically insignificant $(p=0.062$, Table II).

Table I: Demographic and intraoperative data.

\begin{tabular}{l|c|c|c}
\hline Variable & Group A $(n=55)$ & Group B $(\mathrm{n}=55)$ & $\mathrm{p}$-value \\
\hline Age, years (mean \pm S.D) & $44.42 \pm 10.78$ & $44.22 \pm 10.45$ & 0.921 \\
Weight, kg (mean \pm S.D) & $56.76 \pm 9.10$ & $55.29 \pm 8.10$ & 0.374 \\
Gender (male / female) & $29 / 26$ & $22 / 33$ & 0.181 \\
\hline $\begin{array}{l}\text { Duration of surgery, minutes } \\
\text { (mean } \pm S . D)\end{array}$ & $60.20 \pm 5.42$ & $59.45 \pm 5.77$ & 0.486 \\
\hline
\end{tabular}

Table II: Outcome data of study.

\begin{tabular}{l|c|c|c}
\hline Variable & Group A $(\mathrm{n}=55)$ & Group $\mathrm{B}(\mathrm{n}=55)$ & $\mathrm{p}$-value \\
\hline $\begin{array}{l}\text { Postoperative analgesia } \\
\text { duration, hours }\end{array}$ & $0.99 \pm 0.51$ & $16.53 \pm 2.65$ & $<0.001$ \\
\hline $\begin{array}{l}\text { Total tramadol required } \\
\text { within 1 day, mg }\end{array}$ & $124.80 \pm 26.68$ & $31.00 \pm 14.98$ & $<0.001$ \\
\hline $\begin{array}{l}\text { Numeric pain rating scale score } \\
\text { On extubation }\end{array}$ & $1.18 \pm 0.86$ & $0.96 \pm 0.78$ & 0.205 \\
30 minutes & $1.71 \pm 1.08$ & $1.22 \pm 0.78$ & 0.008 \\
1 hour & $1.96 \pm 0.99$ & $1.60 \pm 0.56$ & 0.021 \\
3 hours & $2.89 \pm 1.26$ & $2.20 \pm 1.11$ & 0.003 \\
6 hours & $3.53 \pm 0.90$ & $2.33 \pm 1.04$ & $<0.001$ \\
12 hours & $4.09 \pm 1.09$ & $3.64 \pm 0.87$ & 0.017 \\
24 hours & $4.80 \pm 0.99$ & $4.44 \pm 1.03$ & 0.062 \\
\hline
\end{tabular}

Data is mentioned as mean \pm standard deviation.

\section{DISCUSSION}

In the present study, significant decrease in postsurgical pain and prolongation of postoperative analgesia duration was observed after intraoperative peritoneal irrigation with large volume of diluted bupivacaine. There was substantial decrease in postoperative analgesics requirement. Multimodal approach can be used to manage complex postoperative pain and it is associated with fast recovery with less opioid requirement. 10,11 Diclofenac sodium along with Fentanyl was given to patients, preoperatively. Diclofenac sodium can reduce parietal pain but bupivacaine is useful in controlling visceral pain as observed in the current study. Bupivacaine prolongs the duration of analgesia and it is included in a local anesthetics group known as amide group. Short acting analgesics were found to be more effective as compared to the irrigation of the peritoneal cavity and bed of gall bladder with small volumes of highly concentrated bupivacaine. ${ }^{12,13}$

Jain et al. observed that peritoneal irrigation with large quantity of diluted bupivacaine effectively produced postoperative analgesia. ${ }^{9}$ In their study, mean duration of analgesia in saline group was $0.06 \pm 0.172$ hours and that in bupivacaine group was $19.35 \pm 8.64$ hours $(p<0.001)$. In current study, mean duration of postoperative analgesia in saline group was $0.99 \pm 0.51$ hours and that in bupivacaine group was $16.53 \pm 2.65$ hours $(p<0.001)$. In study by Jain et al., 9 total rescue analgesic requirement within 24 hours in saline group was $123.33 \pm 43.01 \mathrm{mg}$ and that in bupivacaine group was $23.33 \pm 43.01 \mathrm{mg}$ $(p<0.001)$; and in current study, total tramadol required was $124.80 \pm 26.68 \mathrm{mg}$ in saline group and $31.00 \pm 14.98$ $\mathrm{mg}$ in bupivacaine group $(\mathrm{p}<0.001)$.

Peritoneal lavage with local anesthetics was not found to be an efficient method to produce post-LC analgesia, in a Cochrane review. ${ }^{14}$ The reason behind this is thought to be the consumption of small quantity of local anesthetic agents which could not irrigate all of visceral area. No noteworthy results were observed after peritoneal irrigation with bupivacaine by Boddy et al., ${ }^{15}$ which might be due to the fact that they used 10 to $200 \mathrm{ml}$ fluid having $0.1 \%$ to $0.5 \%$ bupivacaine concentration.

Ravishankar et al. compared the postoperative analgesic effects of $20 \mathrm{ml} 0.5 \%$ intraperitoneal bupivacaine at the end of laparoscopic surgery with control $0.9 \%$ saline $20 \mathrm{ml} .^{2}$ They observed bupivacaine group had better postoperative pain relief in the first six hours without any complications. They concluded that $0.5 \%$ bupivacaine irrigation at the surgical bed is effective for postoperative pain relief following cholecystectomy. Javed et al. conducted a study in 2016 and included 110 subjects. They observed that the incidence of postoperative pain, nausea and vomiting were significantly less in the bupivacaine group than those observed in the normal saline group. ${ }^{16}$ Pain score was also significantly lower in the bupivacaine at 2, 4 and 8 postoperative hours. Overall results of theirs study were in accordance with the results observed in our study. Shoulder pain, which is due to the visceral irritation of phrenic nerve following cholecystectomy, was found to be significantly reduced after peritoneal irrigation with bupivacaine, as observed in our study.

Toleska et al. conducted a study on 50 individuals and observed that visual analogue scale (VAS) scores were statistically significantly lower at all times in bupivacaine compared to saline group. 17 There were statistically significant differences in VAS scores between bupivacaine group and saline group at all the time points, i.e. 1 hour, 4 hours, 8 hours, 12 hours and 24 hours postoperatively $(p<0.001)$. These results were also similar to those observed in this study. Intraoperative peritoneal irrigation with bupivacaine is thought to cause postoperative nausea and vomiting, but no such effects were observed in a study conducted by Yari et al.,18 and no such adverse effects were observed in current study.

\section{CONCLUSION}

Large volume of diluted bupivacaine when injected intraperitoneally during laparoscopic cholecystectomy, provides prolonged time pain relief.

\section{ETHICAL APPROVAL:}

Ethical approval was obtained from the Hospital Review Committee. 


\section{PATIENTS' CONSENT:}

Informed consent was signed by every patient before enrollment in the study.

\section{CONFLICT OF INTEREST:}

Authors declared no conflict of interest.

\section{AUTHORS' CONTRIBUTION:}

AM: Conceived idea, study designed. AAK: Data collection, literature review. IA: Data collection, manuscript writing. MU: Data analysis, manuscript writing. TJ: Data collection, literature review. MAS: Proofreading.

\section{REFERENCES}

1. Xu B, Xu B, Zheng WY, Ge HY, Wang LW, Song ZS, et al. Transvaginal cholecystectomy vs. conventional laparoscopic cholecystectomy for gallbladder disease: A meta-analysis. World J Gastroenterol 2015; 21:5393-406.

2. Ravishankar N, Vasudevaiah T, Shivkumar S. Irrigation with bupivacaine at surgical bed for postoperative pain relief after laparoscopic cholecystectomy. Int Surg J 2018; 5:1538-42.

3. Das K, Karateke F, Menekse E, Ozdogan M, Aziret M, Erdem H, et al. Minimizing shoulder pain following laparoscopic cholecystectomy: A prospective, randomized, controlled trial. J Laparoendosc Adv Surg Tech 2013; 23:179-82.

4. Saadati K, Razavi MR, Salman DN, Izadi S. Postoperative pain relief after laparoscopic cholecystectomy intraperitoneal sodium bicarbonate versus normal saline. Gastroenterol Hepatol Bed Bench 2016; 9:189.

5. Yeh CN, Tsai CY, Cheng CT, Wang SY, Liu YY, Chiang KC, et al. Pain relief from combined wound and intraperitoneal local anesthesia for patients who undergo laparoscopic cholecystectomy. BMC Surgery 2014; 14:28.

6. Yang SY, Kang H, Choi GJ, Shin HY, Baek CW, Jung YH, et al. Efficacy of intraperitoneal and intravenous lidocaine on pain relief after laparoscopic cholecystectomy. J Int Med Res 2014; 42:307-19.

7. Choi GJ, Kang H, Baek CW, Jung YH, Kim DR. Effect of intraperitoneal local anesthetic on pain characteristics after laparoscopic cholecystectomy. World J Gastroenterol 2015; 21:13386.

8. Castillo-Garza G, Díaz-Elizondo JA, Cuello-García CA, Villegas-Cabello O. Irrigation with bupivacaine at the surgical bed for postoperative pain relief after laparoscopic cholecystectomy. JSLS 2012; 16:105-11.

9. Jain S, Nazir N, Singh S, Sharma S. A prospective randomised controlled study for evaluation of high-volume low-concentration intraperitoneal bupivacaine for post-laparoscopic cholecystectomy analgesia. Indian J Anaesth 2018; 62:109-14.

10. Kehlet $\mathrm{H}$. Postoperative opioid sparing to hasten recovery what are the issues. Anesthesiol 2005; 102:1083-85.

11. Marret E, Kurdi O, Zufferey $P$, Bonnet F. Effects of nonsteroidal antiinflammatory drugs on patient-controlled analgesia morphine side effects Meta-analysis of randomized controlled trials. Anesthesiology 2005; 102:1249-60.

12. Ahmed BH, Ahmed A, Tan D, Awad ZT, Al-Aali AY, Kilkenny J, et al. Post-laparoscopic cholecystectomy pain effects of intraperitoneal local anesthetics on pain control: A randomized prospective double-blinded placebo-controlled trial. Am Surg 2008; 74:201-9.

13. Bisgaard T. Analgesic treatment after laparoscopic cholecystectomy: A critical assessment of the evidence. Anesthesiol 2006; 104:835-46.

14. Gurusamy KS, Vaughan J, Toon CD, Davidson BR. Pharmacological interventions for prevention or treatment of postoperative pain in people undergoing laparoscopic cholecystectomy. Cochrane Database Syst Rev 2014; 3:CD008261.

15. Boddy AP, Mehta S, Rhodes M. The effect of intraperitoneal local anesthesia in laparoscopic cholecystectomy: A systematic review and meta-analysis. Anesth Analg 2006; 103:682-8.

16. Javed SA, Muham HK. Pre-emptive analgesia in laparoscopic cholecystectomy by intraperitoneal instillation of bupivacain. J Fatima Jinnah Med Uni 2016; 10:56-9.

17. Toleska M, Kartalov A, Kuzmanovska B, Panovski M, Shosholcheva M, Dimitrovski A, et al. Efficacy of intra-peritoneal bupivacaine on pain relief after laparoscopic cholecystectomy. Pril (Makedon Akad Nauk Umet Odd Med Nauki) 2018; 39:123-9.

18. Yari M, Rooshani B, Golfam P, Nazari N. Intraperitoneal bupivacaine effect on postoperative nausea and vomiting following laparoscopic cholecystectomy. Anesthesiol Pain Med 2014; 4:e16710. 